\title{
BMJ Open Effectiveness of pretend medical play in improving children's health outcomes and well-being: a systematic review
}

\author{
Aneesa Abdul Rashid (D) , ${ }^{1}$ Ai Theng Cheong, ${ }^{1}$ Ranita Hisham, ${ }^{2}$ \\ Nurainul Hana Shamsuddin, ${ }^{1}$ Dalila Roslan ${ }^{3}$
}

To cite: Rashid AA, Cheong AT, Hisham R, et al. Effectiveness of pretend medical play in improving children's health outcomes and well-being: a systematic review. BMJ Open 2021;11:e041506. doi:10.1136/ bmjopen-2020-041506

- Prepublication history and additional materials for this paper is available online. To view these files, please visit the journal online (http://dx.doi. org/10.1136/bmjopen-2020041506).

Received 10 June 2020

Revised 22 December 2020

Accepted 07 January 2021

\section{A) Check for updates}

(c) Author(s) (or their employer(s)) 2021. Re-use permitted under CC BY-NC. No commercial re-use. See rights and permissions. Published by BMJ.

${ }^{1}$ Department of Family Medicine, Universiti Putra Malaysia, Faculty of Medicine and Health Sciences, Serdang, Selangor, Malaysia

${ }^{2} \mathrm{~T} J$ Danaraj Medical Library, Universiti Malaya, Kuala Lumpur, Wilayah Persekutuan, Malaysia ${ }^{3}$ Global Health Unit, Ministry of Health Malaysia, Putrajaya, Wilayah Persekutuan, Malaysia

Correspondence to Dr Aneesa Abdul Rashid; aneesa@upm.edu.my

\section{ABSTRACT}

Background The healthcare setting is stressful for many people, especially children. Efforts are needed to mitigate children's healthcare-related anxiety. Medical play using the Teddy Bear Hospital (TBH) concept can expose children to healthcare settings and help them develop positive experiences in these settings. In this role-playing game, children bring their soft toys and act as parents to the 'sick' teddies in a pretend hospital or clinic play setting. The objective of this systematic review is to evaluate the effectiveness of the TBH in improving children's health outcomes and well-being.

Methods We searched the reference lists of included studies from four electronic databases (PubMed, CINAHL, Scopus and Google Scholar) from inception until November 2020. We included pre-post, quasiexperimental and casecontrol studies, as well as randomised controlled trials (RCTs) that discussed medical play using the TBH concept as an intervention. Studies that involved sick patients and used interventions unlike the TBH were excluded. We assessed the quality of the included studies using the Cochrane Collaboration's 'Risk of bias' tool.

Results Ten studies were included in this systematic review. Five specifically investigated the TBH method, while the others involved the same concept of medical play. Only three studies were RCTs. All of the studies report more than one outcome-mostly positive outcomes. Two report lower anxiety levels after intervention. Two found better healthcare knowledge, with one reporting increased feelings of happiness regarding visiting a doctor Two studies found no change in anxiety or feelings, while another two found increased levels of fear and lowered mood after the medical play (which involved real medical equipment).

Conclusions The practice of TBH has mostly positive outcomes, with lower anxiety levels and improved healthcare knowledge. Its effectiveness should be verified in future studies using a more robust methodology. PROSPERO registration number CRD42019106355.

\section{BACKGROUND}

Children visit healthcare facilities for many reasons. Among these are regular check-ups, immunisation or treatments. ${ }^{2}$ These visits have been related to negative reactions among children. ${ }^{2}$ Some studies report that approximately $30 \%$ of adults experience anxiety due

\section{Strengths and limitations of this study}

This review examines the effectiveness of pretend medical play using the Teddy Bear Hospital concept on children's health outcomes and well-being.

- We follow established guidelines and identify 10 interventional studies to assess effectiveness.

- The limitations include a lack of high-quality studies. The risk of bias for random sequence generation was unclear or high for 9 of the 10 studies.

to healthcare visits, to the extent that they are said to have 'white coat syndrome' and experience a rise in blood pressure during medical visits. ${ }^{3}$ Like adults, children also fear the unknown. They tend to create fantasies and distort information due to a lack of accurate knowledge; this generates fear and anxiety. ${ }^{4}$ It has been reported that children who are well informed of a certain condition cope better and have less fear when facing the real situation. ${ }^{5}$ Thus, various efforts have been made to ease children's anxiety and fear regarding the healthcare setting and healthcare personnel. The Teddy Bear Hospital (TBH) is one such effort that uses the concept of medical play. ${ }^{6}$

The TBH incorporates pretend hospital play. Children bring their teddy bears or soft toys to role-play healthcare services. They also incorporate an element of medical play, which allows children to play with and explore medical equipment, mostly in the shape of toys but sometimes using real medical equipment. Medical play is a fun activity that incorporates medical themes. It is initiated by an adult but led by the child; its primary aim is to reduce anxiety in healthcare settings. ${ }^{17}$

In $\mathrm{TBH}$ role-play, children act as the teddy bears' parents, bringing the sick teddy bear to visit a teddy doctor, who is usually played by a medical student or volunteer. The setting is in the form of a clinic or hospital where the play area is filled with pretend or real medical equipment, when appropriate. 
Most TBH games are aimed at healthy children, such as kindergarten students, or conducted during an open day in a specific healthcare centre for health education purposes. ${ }^{5-12}$ The objective of this role-play intervention is to ease the child's anxiety in the healthcare setting and to simultaneously enhance their health knowledge. To our knowledge, there are currently no reviews available demonstrating that $\mathrm{TBH}$ programmes have achieved these outcomes.

Therefore, the overall objective of this review is to determine the effectiveness of medical play in the TBH concept in improving children's health outcomes and well-being.

\section{METHODS}

\section{Study design}

This systematic review was conducted and reported based on the Preferred Reporting Items for Systematic Reviews and Meta-Analyses (PRISMA) guidelines. ${ }^{13}$ This review was registered with PROSPERO. The search strategy can be found in online supplemental file S1.

\section{Search strategy}

We performed an electronic literature search in MEDLINE (PubMed), CINAHL, Scopus and Google Scholar from inception to November 2020. A combination of Medical Subject Headings and free text terms were used for the keywords 'Teddy-Bear Hospital', 'Teddy-Bear Clinic', 'medical play' and 'child'. These keywords had to appear in conjunction in the title, abstract or full text of the article. We also conducted an additional search on the references of relevant articles.

\section{Inclusion and exclusion criteria}

We included all pre-post, quasiexperimental and casecontrol studies, along with randomised controlled trials (RCTs), performed in both community and health settings and discussing the TBH or medical play interventions involving dolls or soft toys and medical equipment. The medical play interventions involving dolls or soft toys and medical equipment were included because they apply the same concept as the TBH. Furthermore, the included studies report on the primary outcomes, including health outcomes such as health knowledge and psychological impacts. We excluded studies that reported sick children in hospital, as well as studies that use interventions other than the TBH concept of soft toys and medical play equipment. As mentioned earlier, since most TBH studies are performed with healthy children, we excluded studies performed with sick children. The concept of TBH is focused on healthy children going for well-check visits, as these visits are common and the experiences may influence children's medical fears. ${ }^{12}$ Furthermore, the psychology of sick, hospitalised children most likely differs from that of healthy children. ${ }^{14}$

\section{Study selection}

The articles obtained from the literature search were imported into EndNote; duplicate articles were removed.
The remaining articles were screened by two teams of reviewers, each composed of two reviewers: DR and AAR and NHS and ATC. Each reviewer independently screened the titles and abstracts of the articles and compared findings with the other team members. Any discrepancies regarding inclusion were discussed between the two team members, with the decision based on the consensus agreed after discussion. In cases where one team could not reach a consensus, the other team provided input. After a paper was identified as relevant, the full text was retrieved. These papers were independently reviewed again by each team member using a spreadsheet of the same format. The spreadsheets were later compared. If there were any discrepancies regarding the articles between the two reviewers in one team, the other team was consulted. The included articles were combined into one spreadsheet.

\section{Data extraction}

Data were extracted from the relevant studies by one reviewer (AAR) and checked by a second reviewer (ATC) on another spreadsheet. Disagreements at any stage were resolved through discussion with a third reviewer (NHS or DR). We extracted data on the following subjects: setting, objective, population, intervention/approach, measuring tools, outcomes of interest, $\mathrm{N} / \mathrm{N}$ intervention, $\mathrm{N} / \mathrm{N}$ control, results and conclusion.

\section{Quality assessment}

The quality of the methodology used in the studies was assessed using the Cochrane Collaboration's 'Risk of bias' tool. ${ }^{15}$ Each included study was assessed based on several characteristics: (A) selection bias (randomisation and allocation concealment), (B) performance bias (blinding of participants or personnel), (C) detection bias (blinding of outcome assessment), (D) attrition bias (incomplete outcome data, both long term and short term), and (E) reporting bias (selective reporting). All studies were critically appraised in duplicate by the two reviewers (AAR and ATC) and presented to the other research team members. We discussed any disagreements to reach a consensus and produce a combined assessment result.

\section{Data analysis}

The extracted data were analysed via narrative analysis. We did not perform meta-analysis because the tools for measuring outcomes varied among the studies; thus, the results could not be pooled.

\section{RESULTS}

\section{Study selection}

Our literature search yielded 16306 studies from inception to November 2020. We identified 12522 articles after excluding 3784 duplicates. Of these, 12473 were excluded. The excluded articles had titles and abstracts outside the scope of our study. The remaining 49 studies 


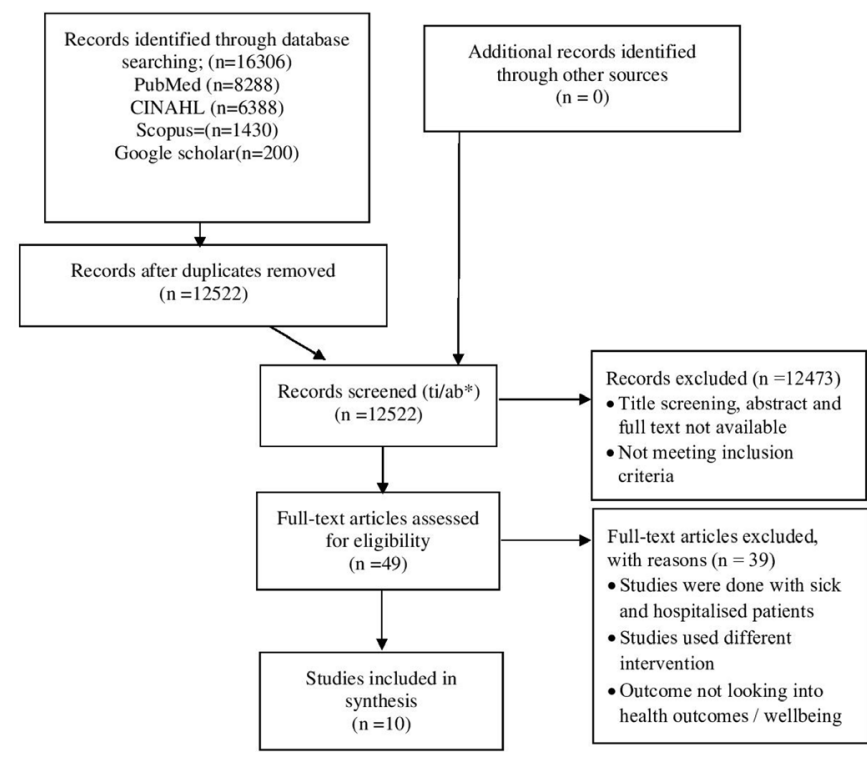

Figure 1 Preferred Reporting Items for Systematic Reviews and Meta-Analyses (PRISMA) flow chart detailing the search strategy used. ti/ab, title/abstract.

were available for retrieval in full text. Ten out of 49 studies were selected based on the inclusion and exclusion criteria. Studies were excluded because they investigated sick children in the hospital, they did not use TBH or similar interventions, or their outcomes did not align with the study objectives. The PRISMA flow diagram and the exclusion criteria are presented in figure 1.

\section{Description of included studies}

Out of the 10 studies we included, three were RCTs, ${ }^{1} 1617$ three were non-randomised trials with a control group ${ }^{5818}$ and the remaining were pre-post studies. ${ }^{9-1119}$ These studies had population groups ranging from 30 to 543 participants aged 2-12. Six of the included studies involved TBH as an intervention, ${ }^{5-12}$ while the remaining four studies used medical play interventions. ${ }^{16-18}$ This medical play applied a similar concept; three studies involved dolls with real medical equipment, ${ }^{1718}$ while another study used medical play with a collection of medical equipment. ${ }^{16}$ Four studies were conducted in North America (three in the USA ${ }^{1617}$ and one in Canada ${ }^{19}$ ), Three in Europe (one in the UK, ${ }^{10}$ one in the Netherlands ${ }^{9}$ and one in Germany ${ }^{5}$ ) and one each in Singapore, ${ }^{11}$ Brazil $^{18}$ and Israel. $^{8}$ The studies were conducted between 2002 and 2018 and involved mostly medical or veterinary students in TBH settings or researchers in medical play settings. An overview of the studies is given in online supplemental file S2.

\section{Quality of studies}

The risk of bias for random sequence generation was unclear or high for 9 out of 10 studies; one study was an RCT. ${ }^{1}$ All studies had a high risk of bias for allocation concealment and performance bias. Most studies did not conduct randomisation for their participants. Apart from that, concealing the intervention could not be done with TBH or medical play. Regarding detection bias, only $20 \%$

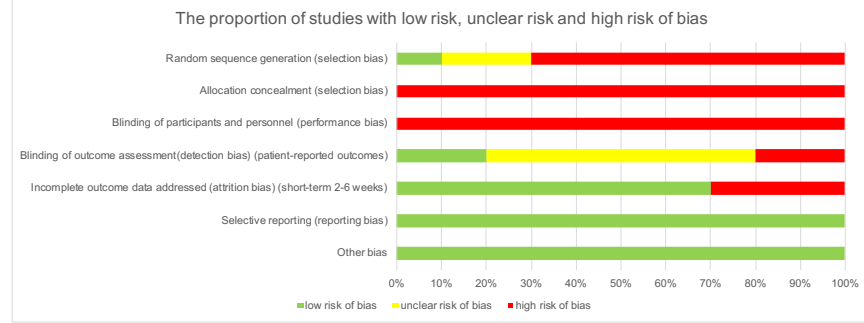

Figure 2 The proportion of studies with low risk, unclear risk and high risk of bias.

of the studies carried a low risk of bias, with the assessors blinded from the group arrangements of the interventions. ${ }^{1}{ }^{17}$ Three studies were found to have a high risk of reporting bias because a proportion of data were excluded from the results analysis. ${ }^{9-11}$ All studies carried a low risk of bias for selective reporting; no other biases were found in the studies. Figure 2 shows the proportion of studies with a low risk, unclear risk or high risk of bias. The assessment of biases in the individual studies is shown in online supplemental file S3.

\section{Results of individual studies \\ Children's feelings}

Overall, the studies showed mixed results. Seven studies measured the children's feelings, using mostly the level of anxiety and fear as the outcomes. Four studies (one non-randomised trial with a control group and three prepost studies) concluded that the children had more positive feelings with lower anxiety levels after the TBH. $^{8-11}$ Three more studies (two RCTs and one pre-post study) concluded otherwise- the RCTs ${ }^{17}$ showed that medical play intervention had lowered the children's mood and increased the level of fear. The pre-post study ${ }^{19}$ showed no effect of TBH on the children's level of fear.

\section{Children's behaviour}

Two RCTs found that the participants in the medical playgroup were more difficult during triage procedures than the children in the medical information group, the typical playgroup or the control group. ${ }^{17}$ Two other studies (one RCT and one non-randomised trial with a control group) showed positive outcomes for medical play intervention. ${ }^{16} 18$ They reported the children as being more alert and demonstrating greater acceptance of the procedure (immunisation) after the intervention. ${ }^{1618}$ Thus, the results are mixed.

\section{Children's healthcare knowledge}

Two studies discuss the effects of the TBH on children's healthcare knowledge. Both of these studies (one nonrandomised trial with a control group and one pre-post study) conclude that children had improved healthcare knowledge after the TBH intervention. ${ }^{511}$ Therefore, these two studies investigating children's knowledge showed positive results.

A detailed summary of the results of individual studies is included in online supplemental file S4. 


\section{Others}

Although we did not assess outcomes for parents, it is notable that one study reported that parents' level of worry significantly correlated with their children's perceived level of worry regarding seeing the doctor. ${ }^{1}$ The other studies showed either no significant associations with parents talking to their children; and perception of the children's worry to see the doctor between the control group and intervention group, or showed parents' level of worry positively correlated with their perception of their children's level of worry. ${ }^{16}$ The other eight studies either did not involve parents or did not report any findings on the parents.

\section{DISCUSSION}

TBH is a popular project that has been performed around the world, primarily to reduce children's fear and anxiety regarding healthcare professionals and hospitals through pretend medical play. The strength of our review is that it represents the first effort to summarise the effectiveness of TBH programmes and the concept of medical play in improving children's health outcomes and well-being. Because the $\mathrm{TBH}$ has become a popular concept for educating children, a review examining its effectiveness is important.

In general, the studies included in this review show a high level of selection bias and performance bias. However, this finding is unavoidable due to the nature of the intervention, which involves children participating in physical activities related to the $\mathrm{TBH}$ intervention or medical play. Detection bias was high because most of the studies did not describe the methods for blinding the outcome assessors.

Our review suggests that medical play using the TBH concept has a positive effect on children's health outcomes and well-being, particularly for reducing anxiety and fear. This is probably because playful activities are important in child development and learning, especially regarding social interaction. Therefore, medical play helps them become more open to healthcare personnel and surroundings. ${ }^{18} 19$ Exploration of medical items in medical play reportedly helps children express themselves more clearly, thereby improving psychological well-being, specifically in the healthcare setting. ${ }^{16}{ }^{17}$ This method of simulating a scenario is quite common and is used primarily for teaching in medical and healthcare environments. ${ }^{2021}$ For children specifically, the term 'experiential learning' is more commonly used; this practice has proven to be effective. For example, children actively participating in growing fruits and vegetables in their school gardens show greater improvements in nutrition knowledge while exhibiting increased preferences for eating fruits and vegetables, compared with those who were only taught nutrition but not exposed to gardening activities. $^{22} 23$

Considering that medical play is supervised, this may constitute another factor in anxiety reduction. Another reason for this reduction is the non-threatening environment of the TBH, which facilitates 'control over a possible threatening situation'. Through medical play, TBH can also significantly improve children's healthcare knowledge. This is unsurprising - as mentioned earlier, children learn well via playful activities. Furthermore, the role-playing component enhances the effectiveness of learning. ${ }^{518}$

However, two studies conducted by Burns-Nader et al found a contradictory effect of medical play intervention on children's health outcomes. This involved a reported increase in fear and a depressed mood by the children after the play therapy and after the doctor's visit (compared with baseline). ${ }^{1} 17$ This discrepancy in the results suggests the need for further research to determine which components of medical play interventions affect the final outcomes of the intervention. The medical play in both studies involved real medical equipment without any toys - in contrast to the equipment used in a $\mathrm{TBH}$ setting, which consists mostly of toys made to resemble medical equipment.

Further studies should explore whether the physical involvement of children in role-playing-or, rather, the medical information obtained through these activitiesserves as the primary factor in reducing children's fear and anxiety.

We hypothesise that the lack of consistency in the studies' findings may result from having third-party personnel assess the children's responses, instead of having the children self-report outcomes. The children's distress behaviours were assessed by nurses during triage, which may have induced greater fear among children than in other studies, where the outcomes were usually reported by the children themselves or assessed by nonmedical personnel.

Significant improvements in healthcare-related knowledge were seen in studies performed by Leonhardt et al and Victorine et $a l^{5}{ }^{10}$ This indicates that TBH may be an effective method in programmes aimed at raising children's awareness of health-related issues. For example, $\mathrm{TBH}$ can be used to teach children about healthy living to prevent childhood obesity, which is rising globally. Early educational intervention is important for preventing adverse health outcomes later in adulthood. ${ }^{24}$ The implementation of these programmes, however, requires cooperation from various parties: healthcare professionals, parents, teachers and authorities.

Further clinical implications of this study include the potential use of the $\mathrm{TBH}$ as a tool for teaching children about personal safety to prevent child sexual abuse, in view of the drastic rise in the number of child sexual abuse cases that is occurring nationally and globally. ${ }^{25} 26$

\section{Limitations}

This review includes a relatively small number of studies; most are pre-post studies. This limitation may impact the generalisability of the findings for future implementations. There are also issues surrounding obtaining consent for the children-they are unable to consent to 
their involvement in these interventions. Furthermore, some studies found a negative effect on the children.

\section{Implications of the review on practice and further research}

We have found that the concept of the TBH-which involves pretend medical play and using toy or (occasionally) real medical equipment-lowers children's anxiety levels and improves the children's healthcare knowledge. Therefore, the TBH may constitute a potential public health strategy for improving health interventions, specifically as a health education tool for teaching preschool and primary school children about topics such as immunisation, a healthy lifestyle, or sexual and physical abuse.

Our review indicates that the quality of the studies was not satisfactory, as most of the studies were pre-post studies. Future studies should adopt a more robust methodology to examine the effects of the TBH concept of medical play intervention.

\section{CONCLUSION}

TBH interventions have a positive outcome for children's emotions and healthcare knowledge, according to most of the studies. Its effectiveness should be verified in future studies using a more robust methodology.

Correction notice This article has been corrected since it first published. The provenance and peer review statement has been included.

Acknowledgements We would like to thank Lee Yan Lum and Aina Nadhirah Affandi, our research assistants, for their assistance in this systematic review.

Contributors AAR, ATC, NHS and DR designed the study. HR was responsible for conducting the literature search. All authors participated in the selection of the included studies. AAR, ATC, NHS and DR were responsible for data extraction, study appraisal, data analysis and results interpretation. All authors contributed to drafting the manuscript. The final manuscript was approved by all authors.

Funding This research was funded by Universiti Putra Malaysia internal grant (project code: GP-IPM/2018/9640400).

Disclaimer The funding organisation was not involved in conducting or writing this systematic review.

Competing interests None declared.

Patient consent for publication Not required

Provenance and peer review Not commissioned; externally peer reviewed.

Data availability statement All data relevant to the study are included in the article or uploaded as supplementary information.

Supplemental material This content has been supplied by the author(s). It has not been vetted by BMJ Publishing Group Limited (BMJ) and may not have been peer-reviewed. Any opinions or recommendations discussed are solely those of the author(s) and are not endorsed by BMJ. BMJ disclaims all liability and responsibility arising from any reliance placed on the content. Where the content includes any translated material, BMJ does not warrant the accuracy and reliability of the translations (including but not limited to local regulations, clinical guidelines, terminology, drug names and drug dosages), and is not responsible for any error and/or omissions arising from translation and adaptation or otherwise.

Open access This is an open access article distributed in accordance with the Creative Commons Attribution Non Commercial (CC BY-NC 4.0) license, which permits others to distribute, remix, adapt, build upon this work non-commercially, and license their derivative works on different terms, provided the original work is properly cited, appropriate credit is given, any changes made indicated, and the use is non-commercial. See: http://creativecommons.org/licenses/by-nc/4.0/.

\section{ORCID iD}

Aneesa Abdul Rashid http://orcid.org/0000-0002-7944-1364
REFERENCES

1 Burns-Nader ES. The effects of medical play on reducing fear, anxiety, and procedure distress in school-aged children going to visit the doctor. University of Alabama Libraries, 2011.

2 Lerwick JL. Minimizing pediatric healthcare-induced anxiety and trauma. World J Clin Pediatr 2016:5:143-50.

3 Alves LMM, Nogueira MS, Godoy Sde, et al. Prevalence of white coat hypertension in primary health care. Arq Bras Cardiol 2007;89:28-35.

4 Santen L, Feldman T. Teddy bear clinics: a huge community project. MCN Am J Matern Child Nurs 1994;19:102-6.

5 Leonhardt C, Margraf-Stiksrud J, Badners L, et al. Does the 'Teddy Bear Hospital' enhance preschool children's knowledge? A pilot study with a pre/post-case control design in Germany. J Health Psychol 2014;19:1250-60.

6 Kaufman J, Modak M, Moylan S. The Teddy bear hospital in Australia. J Paediatr Child Health 2012;48:541-2.

7 McCue K. Medical play: an expanded perspective. Child Health Care 1988;16:157-61.

8 Bloch YH, Toker A. Doctor, is my teddy bear okay? The "Teddy Bear Hospital" as a method to reduce children's fear of hospitalization. Isr Med Assoc J 2008;10:597-9.

9 Ottenheim M, Sommeren Rvan. The Teddy bear Hospital. How to influence the attitude of kindergarten children towards doctors, hospitals and falling ill, 2018. Available: /paper/The-Teddy-BearHospital.-How-to-influence-the-of-Ottenheim-Sommeren/778b811ab 7b57a3da3a35d58a664ed3a64d7f774

10 Victorine A, Wong Z, Geilani J, et al. Teddy Bear Hospital (TBH)reducing children's fear of doctors and hospital environment. PEDIATRICS2002;110:e33.

11 Ong L, Chua KH, Soh JY, et al. Healthcare encounters in young children: impact of Teddy bear Hospital, Singapore. TAPS 2018;3:24-30.

12 Dalley JS, Creary PR, Durzi T, et al. An interactive Teddy bear clinic tour: teaching veterinary students how to interact with young children. J Vet Med Educ 2017;44:302-15.

13 Moher D, Liberati A, Tetzlaff J, et al. Preferred reporting items for systematic reviews and meta-analyses: the PRISMA statement. PLoS Med 2009;6:e1000097.

14 Rennick JE, Rashotte J. Psychological outcomes in children following pediatric intensive care unit hospitalization: a systematic review of the research. J Child Health Care 2009;13:128-49.

15 Higgins JPT, Green S. Assessing risk of bias in included studies. In: Cochrane handbook for systematic reviews of interventions. Version 5.1.0, 2017

16 Brown JC. Group medical play for reducing stress and improving mood in children going to visit the pediatrician. University of Alabama Libraries, 2012.

17 Burns-Nader S, Hernandez-Reif M, Thoma SJ. Play and video effects on mood and procedure behaviors in school-aged children visiting the pediatrician. Clin Pediatr 2013;52:929-35.

18 Pontes JED, Tabet E, Folkmann Maria Áurea Dos Santos, et al. Therapeutic play: preparing the child for the vaccine. Einstein 2015;13:238-42.

19 Dalley JS, McMurtry CM. Teddy and I get a check up: a pilot educational intervention teaching children coping strategies for managing procedure-related pain and fear. Pain Res Manag 2015

20 Jeffries PR, Bambini D, Hensel D, et al. Constructing maternal-child learning experiences using clinical simulations. J Obstet Gynecol Neonatal Nurs 2009;38:613-23.

21 Schreiber J, Moerchen VA, Rapport MJ, et al. Experiential learning with children: an essential component of professional physical therapy education. Pediatr Phys Ther 2015;27:356-67.

22 Parmer SM, Salisbury-Glennon J, Shannon D, et al. School gardens: an experiential learning approach for a nutrition education program to increase fruit and vegetable knowledge, preference, and consumption among second-grade students. J Nutr Educ Behav 2009;41:212-7.

23 Heim S, Stang J, Ireland M. A garden pilot project enhances fruit and vegetable consumption among children. J Am Diet Assoc 2009;109:1220-6.

24 Reilly JJ. Childhood obesity: an overview: childhood obesity. Child Soc 2007;21:390-6.

25 Pereda N, Guilera G, Forns M, et al. The prevalence of child sexual abuse in community and student samples: a meta-analysis. Clin Psychol Rev 2009;29:328-38.

26 Singh HS, Yiing WW, Nurani HN. Prevalence of childhood sexual abuse among Malaysian paramedical students. Child Abuse Negl 1996;20:487-92. 